\title{
O significado da música para os pacientes no período pós-operatório
}

\author{
The meaning of music for patients in the post-operating period \\ El significado de la música para pacientes en el postoperatorio
}

Recebido: 21/05/2021 | Revisado: 28/05/2021 | Aceito: 07/06/2021 | Publicado: 21/06/2021

Cristiane de Matos Nogueira

ORCID: https://orcid.org/0000-0002-0180-9034

Universidade de São Paulo, Brasil

E-mail: cristianematosnogueira@gmail.com

Patrícia Costa dos Santos da Silva

ORCID: https://orcid.org/0000-0001-9643-1865

Universidade Federal de Uberlândia, Brasil

E-mail: patriciacosta@ufu.br

Lívia Ferreira Oliveira

ORCID: https://orcid.org/0000-0003-1978-7889

Universidade Federal de Uberlândia, Brasil E-mail:liviaenfermg@yahoo.com.br

Jéssica Santos de Lima

ORCID: https://orcid.org/0000-0002-4931-193X

Hospital e Maternidade Santa Clara, Brasil

E-mail: jessicalimasdl@gmail.com

Bruna Aparecida Rodrigues Duarte

ORCID: https://orcid.org/0000-0003-0487-455X

Universidade Federal de Uberlândia, Brasil E-mail: brunaap150@ hotmail.com

Luana Araújo Macedo Scalia

ORCID: https://orcid.org/0000-0003-1000-8738

Universidade Federal de Uberlândia, Brasil

E-mail: luanaamacedo@yahoo.com.br

Carla Denari Giuliani

ORCID: https://orcid.org/0000-0001-5598-2230

Universidade Federal de Uberlândia, Brasil

E-mail: denari.carla013@gmail.com

\begin{abstract}
Resumo
Objetivo: analisar o significado da música para os pacientes no período pós-operatório. Método: estudo de abordagem qualitativa, no qual 22 pacientes, em período pós-operatório, participaram de encontros musicais. Os encontros musicais foram realizados por um grupo de voluntários, sendo aplicada a música à capela, execução de modo vocal sem acompanhamento instrumental, alternando com o modo acústico, utilizando violões acústicos Ukulele ${ }^{\circledR}$, Gianni®, realizando 12 encontros, com duração de 40 minutos. Após a intervenção, os participantes responderam uma entrevista e, posteriormente, os dados foram analisados a partir da análise temática e auxílio do software Iramute $Q \circledR$. Resultados: com os dados analisados, foi possível compreender a percepção dos atores sociais em relação à música, emergindo como resultados as categorias: a música e a espiritualidade; o acolhimento; a influência no estado emocional e recordações. Conclusão: conclui-se que a música pode ser considerada um instrumento capaz de evocar emoções e despertar sentimentos, favorecendo ao bem-estar e a alegria, produzindo um ambiente que remete ao aconchego e ao conforto, contribuindo assim na humanização da assistência de enfermagem.
\end{abstract}

Palavras-chave: Música; Pós-operatório; Enfermagem.

\begin{abstract}
Objective: to analyze the meaning of music for patients in the postoperative period. Method: a qualitative study, in which 22 patients in the postoperative period participated in musical meetings. The musical meetings were held by a group of volunteers with music being applied to the chapel, performing in a vocal manner without instrumental accompaniment, alternating with the acoustic mode, using Ukulele ${ }^{\circledR}$, Gianni ${ }^{\circledR}$ acoustic guitars, performing 12 meetings, lasting 40 minutes. After the intervention, the participants answered an interview and subsequently the data were analyzed using the thematic analysis and the aid of the IramuteQ ${ }^{\circledR}$ software. Results: with the analyzed data, it was possible to understand the perception of social actors in relation to music, with the following categories emerging: music and spirituality; the reception; the influence on emotional state and memories. Conclusion: it is concluded that music can be considered na instrument capable of evoking emotions and arousing feelings, favoring well-being and joy, producing and environment that refers to warmth and comfort, thus contributing to the humanization of nursing care.
\end{abstract}


Keywords: Music; Postoperative Care; Nursing.

\begin{abstract}
Resumen
Objetivo: analizar el significado de la música para los pacientes en el postoperatorio. Método: estudio cualitativo, en el que 22 pacientes en el postoperatorio participaron en encuentros musicales. Los encuentros musicales fueron realizados por un grupo de voluntarios con música aplicada a la capilla, actuando de manera vocal sin acompañamiento instrumental, alternando con la modalidad acústica, utilizando Ukulele®, guitarras acústicas Gianni®, realizando 12 encuentros de 40 minutos de duración. Tras la intervención, los participantes respondieron a una entrevista y posteriormente se analizaron los datos mediante el análisis temático y la ayuda del software IramuteQ ${ }^{\circledR}$. Resultados: con los datos analizados fue posible comprender la percepción de los actores sociales en relación a la música, emergiendo las siguientes categorías: música y espiritualidad; la recepción; la influencia sobre el estado emocional y los recuerdos. Conclusión: se concluye que la música puede ser considerada un instrumento capaz de evocar emociones y despertar sentimientos, favoreciendo el bienestar y la alegría, produciendo un ambiente que remite a la calidez y el confort, contribuyendo así a la humanización del cuidado de enfermería.
\end{abstract}

Palabras clave: Música; Cuidados Posoperatorios; Enfermería.

\title{
1. Introdução
}

Alguns procedimentos cirúrgicos requerem hospitalização, sendo que o ambiente hospitalar, muitas vezes, é visto como um lugar triste e sem vida, devido à ruptura das atividades do cotidiano, ao afastamento do convívio social, bem como à inserção de uma rotina hospitalar (Nogueira, et al., 2018).

Nesse sentido, pode surgir a ansiedade no período pré-operatório, chegando, inclusive, a influenciar na intensidade da dor pós-operatória e a necessidade de anestesia e de analgesia. Em certas situações, a ansiedade pode até aumentar a morbidade pós-operatória (Stamenkovic, et al., 2018).

Com o intuito de superar uma assistência fragmentada e de minimizar efeitos advindos de um ambiente desumanizado, torna-se essencial que as práticas de saúde exercitem estratégias alternativas de cuidado (Seki \& Galheigo, 2010). Dessa forma, a música, aplicada durante um tratamento de saúde, possibilita distração e produz relaxamento, promovendo, assim, um ambiente de acolhimento e de interação coletiva (Bergold \& Alvim, 2011).

Resultados demonstram que a música tem sido utilizada como importante ferramenta de cuidado no contexto hospitalar, interferindo positivamente nos sinais vitais e na percepção da dor no período pós-operatório (Teixeira, et al., 2018).

Além disso, a música é capaz de promover a descontração e de desenvolver um ambiente propício para a expressão verbal, conduzindo ao diálogo, ao compartilhamento de ideias, o que gera conhecimento e novos sentidos para as pessoas (Bergold \& Alvim, 2011).

Considerando-se os efeitos fisiológicos da música no organismo e no sistema límbico, cabe destacar que este desempenha um importante papel nas emoções, na motivação e na afetividade. Assim, é crucial o desenvolvimento de pesquisas científicas que considerem o caráter processual das reflexões e o significado das vivências, normalmente orientadas pelas metodologias de pesquisa qualitativa (Campos \& Nakasu, 2016).

Diante desse contexto, o objetivo do presente estudo foi analisar o significado da música para pacientes no período pós-operatório.

\section{Metodologia}

O presente estudo trata-se de uma abordagem qualitativa do tipo descritiva e exploratória, realizada em um Hospital Universitário do setor público, localizado no Triângulo Mineiro, em que os dados foram coletados por meio de entrevista com 22 pacientes hospitalizados em uma enfermaria cirúrgica, após a realização de cirurgias, os quais vivenciaram a ação musical da instituição por meio de um grupo de voluntários que cantam semanalmente em diversos setores de internação. Cada encontro musical teve duração de cerca de 40 minutos em um período de 12 semanas. Utilizou-se a música à capela, do tipo religiosa e/ou música popular brasileira com execução de modo vocal sem acompanhamento instrumental, alternando com o 
modo acústico, utilizando violões acústicos Ukulele ${ }^{\circledR}$, Gianni ${ }^{\circledR}$ de cordamento de náilon. O recrutamento dos atores sociais foi realizado por meio de um convite verbal e explicado como funcionaria a entrevista. Após a assinatura do Termo de Consentimento Livre e Esclarecido (TCLE), iniciava-se o processo. Durante as entrevistas foram coletados dados socioeconômicos como: sexo, renda familiar, situação conjugal e nível de escolaridade e para o desenvolvimento do presente estudo, definiu-se a seguinte pergunta norteadora: Qual o significado da música para os pacientes hospitalizados no período pós-operatório? As entrevistas foram gravadas e, posteriormente, transcritas na íntegra a fala dos pacientes a respeito da experiência musical. Cada entrevista foi realizada uma única vez, com tempo de duração cerca de 40 minutos, gravada por meio de um aplicativo de voz da Samsung-Galaxy Ace GTS5830B®. Vale ressaltar que, antes de iniciar as entrevistas, foram feitas as avaliações das funções cognitivas, utilizando-se o Mini Exame do Estado Mental (MINIMENTAL) (Folstein, et al., 1975; Trindade, et al., 2013), instrumento dotado de 30 questões, sendo que a pontuação varia de zero (maior grau de comprometimento cognitivo) até 30, sendo ajustado de acordo com o nível de escolaridade dos pacientes.

Foram convidadas inicialmente 25 pessoas e após aplicação de critérios de inclusão e exclusão foram entrevistadas 22 pessoas. Esse número foi considerado suficiente através dos critérios de saturação de dados com o intuito de verificar que as informações obtidas não apresentavam informações novas (Costa, et al., 2008).

Os critérios de inclusão foram pacientes maiores de 18 anos de idade, em período pós-operatório de qualquer procedimento cirúrgico e que participaram pelo menos de um dos encontros musicais desenvolvidos pelo grupo de voluntários. Os critérios de exclusão foram pacientes que não responderam ao questionário socioeconômico e/ou a pergunta norteadora e aqueles que apresentaram baixa capacidade cognitiva da avaliação do MINIMENTAL.

A coleta de dados ocorreu no período de março a julho de 2018. Ao término da coleta de dados, as entrevistas foram transcritas na íntegra de agosto a novembro de 2018. A seguir, analisou-se o conteúdo que compreendeu as seguintes etapas:1) pré-análise; 2) exploração do material e 3) tratamento dos resultados e interpretação (Minayo, 2010).

Para facilitar a compreensão e a clareza dos dados analisados, utilizou-se o software IramuteQ. A partir da análise temática proposta por Bardin (2011) e do auxílio do software IramuteQ, os dados foram organizados, de modo a permitir compreender a percepção dos atores sociais em relação à música.

O estudo foi aprovado pelo Comitê de Ética e Pesquisa da Universidade Federal de Uberlândia, por meio do Parecer $\mathrm{n}^{\mathrm{o}} 1.833 .534$.

\section{Resultados}

De acordo com os resultados de avaliação socioeconômica, dentre os 22 (100\%) participantes do estudo, observou-se que $11(50,0 \%)$ eram do sexo feminino e $11(50,0 \%)$ do sexo masculino. Com relação à renda familiar $18(81,8 \%)$ participantes apresentaram renda familiar de um a dois salários mínimos e $4(18,2 \%)$ de três salários mínimos. Quanto a situação conjugal, $15(68,2 \%)$ participantes eram casados, $3(13,6 \%)$ eram viúvos, $2(9,1 \%)$ solteiros e 2 (9,1\%) divorciados. Em relação ao nível de escolaridade, a maioria dos participantes, 12 (54,5\%), realizou o ensino fundamental incompleto, seguido de $4(18,0 \%)$ participantes que cursaram o ensino fundamental completo, $3(14,0 \%)$ participantes que cursaram o ensino médio incompleto, $2(9 \%)$ o ensino superior completo e $1(4,5 \%)$ participante que cursou o ensino médio completo.

\subsection{A percepção dos atores sociais em relação à música}

Com o intuito de facilitar a compreensão e a clareza dos dados analisados, elaborou-se, por meio do software IramuteQ, uma nuvem de palavras (Figura 1) que evidencia as principais palavras mencionadas, o que permitiu uma avaliação geral da percepção dos atores sociais do presente estudo. 
Figura 1: Principais palavras mencionadas pelos atores sociais, Uberlândia - MG, 2021.

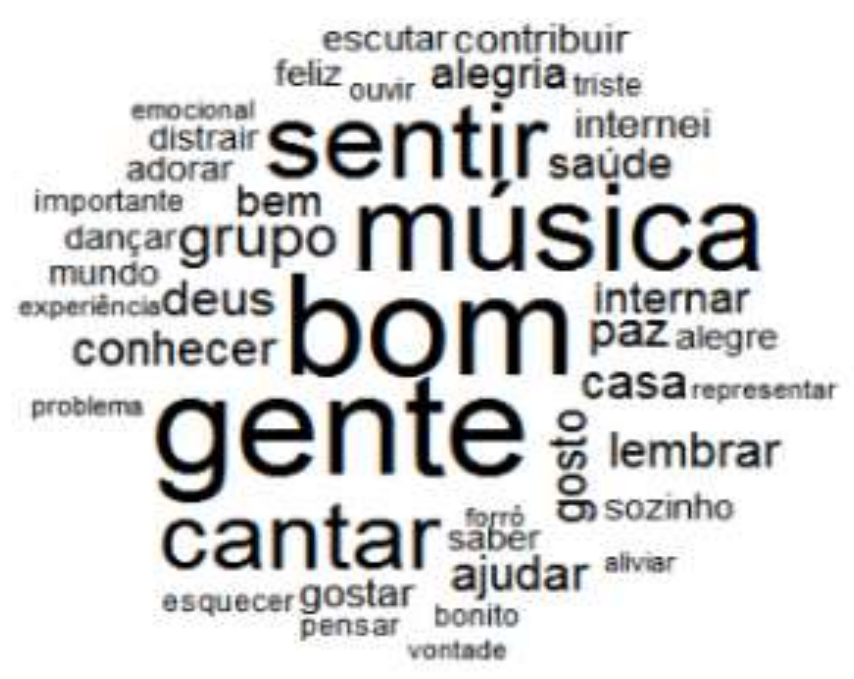

Fonte: Autores (2021).

As palavras com maior frequência foram Gente, Bom, Música, Sentir e Cantar, dentro das entrevistas, o que leva a perceber a música como ferramenta de humanização, de diminuição de dor e da ansiedade, além de proporcionar bem-estar, muitas vezes relacionado com a lembrança do lar e de sua rede de apoio ou, até mesmo, lembranças da infância, consequentemente, podendo auxiliar na recuperação pós-cirúrgica. Tais aspectos encontrados conversam com a definição da Prática Integrativa e Complementar em saúde.

Durante a análise dos dados, emergiram as seguintes categorias que serão discutidas: a música e a espiritualidade; o acolhimento; a influência no estado emocional e recordações.

\subsubsection{A música e espiritualidade}

A música oferecida durante os encontros musicais proporcionou bem-estar e alegria, especialmente em relação ao repertório religioso/espiritual, o que gerou conforto, reflexão e motivação. Os discursos seguintes abordam o sentimento de estar mais próximo de Deus:

(...) eu sinto Deus em primeiro lugar (...) senti mais perto de Deus. P2

(...) traz muita invocação com Deus, me sinto tão bem quando eu escuto a palavra do Senhor. Sei que o Senhor está sempre comigo, segurando a minha mão. P6

É perceptível, por meio dos relatos, como as pessoas se sentiram tocadas pela música e como foram confortadas, o que minimiza sentimentos de desconforto, que podem ser gerados pela dor pós-operatória e pela ausência dos elementos da casa dos participantes.

\subsubsection{Acolhimento}

É possível observar a música como instrumento de acolhimento aos pacientes hospitalizados, ao proporcionar um ambiente de conforto e de aconchego, sentindo-se amparados e conscientes de que alguém, além da família, se preocupa com eles: 
É uma experiência muito boa de saber que tem alguém que se preocupa com você, que te quer levar um conforto, que quer te levar alegria, é muito bom, né, pra mim, não tem explicação, muito bom. P1

(...) para não ter solidão, escutava música em casa, pois me sentia sozinho e, quando escuto música, sinto que não estou sozinho. P4

Há uma paz que senti, senti acolhida. P7

As falas mostram a importância do acolhimento que acontece por meio da música, quando o paciente relata que se sentia sozinho e, através da música, essa sensação acaba por se dissipar.

\subsubsection{Influência no estado emocional e recordações}

A música exerce influência no estado emocional, pois evoca emoções e desperta sentimentos, traz sensações de alegria, de bem-estar, de fortalecimento, de aumento de autoestima, de bom humor e de alívio da tristeza. Os depoimentos evidenciam essa influência quanto ao estado emocional:

(...) melhora o emocional da gente, o espiritual independente de religião, acalma né. (...) melhora seu humor, te dá paz, serenidade, te faz pensar que é pra melhorar que você, tá aqui ne. P7

(...) senti muita alegria, muita alegria, senti fortificada com cantoria deles, com a letra de uma música deles, senti que é importante pra mim. $\mathrm{P} 14$

Traz paz, a gente fica mais alegre, né, feliz, porque a gente fica se sentindo triste, sozinha no hospital, e aí com as pessoas cantando a gente fica com um pouquinho mais de alegria, de esperança. P18

(...) a música, de qualquer forma, ela acaba ajudando a gente, esquecer dos problemas e dá vontade de viver mais, de querer abraçar o mundo, e aí dá mais força pra gente que podemos vencer a luta, né, a batalha da vida. P21

Além disso, a música tem a capacidade de despertar e de fazer reviver as lembranças e as sensações agradáveis, transcendendo a temporalidade existencial, fazendo-os recordar da juventude e dos momentos marcantes da vida:

Lembra minha juventude, mais jovem, sendo que eu não seja tão velha, mais relembra as amizades, aquela coisa de sair, saía aquela turma, então isso, aí, lembrei lá de casa, do marido, do meu filho que tá lá e hoje está aqui comigo. P3

Me lembrou que todo sábado eu ia para o forró só para dançar essa música. Quando chegava lá, até esquecia que estava lá, nem via o tempo passar. P5

Saudades das coisas boas da vida. P13

(...) lembrei de quando ouvia as músicas do Roberto Carlos, recordei dos bons tempos de quando era jovem e de como conquistei minha esposa. P20

(...) ah, é bom que tira um pouco do clima hospitalar, né, a música traz boas memórias, e aí eu acho que é isso aí (...) coisas do passado que aconteceu de bom, até mesmo do presente, né (...) P21 


\section{Discussão}

A análise do significado da música para os pacientes no período pós-operatório permitiu a construção de três categorias: espiritualidade, acolhimento, influência no estado emocional e recordações. Dados semelhantes foram identificados no estudo realizado durante o pré-operatório desta mesma instituição (Silva, et al., 2019), quando emergiram duas unidades temáticas intituladas: Relação mediada: a música como elemento terapêutico e a Música e a dimensão transcendental.

Em relação à espiritualidade, o presente estudo mostra que os encontros musicais geraram bem-estar e alegria. Principalmente quanto ao repertório religioso, os discursos abordam o sentimento de proximidade com Deus. Nesse sentido, a música estabelece estreita relação com a espiritualidade ao sensibilizar os afetos, as emoções e a manifestação dos sentimentos, aproximando-os de Deus, ao trazer momentos de introspecção para enfrentar os desafios de sua existência. A partir dessa percepção, a música permite desvelar o próprio sentido existencial e até mesmo ajudar no enfrentamento de situações de maior dificuldade na vida, pois possibilita à pessoa hospitalizada expressar seus sentimentos, levando-a a uma experiência transcendental. Desse modo, possibilita transcender as barreiras da enfermidade e da limitação física e vislumbrar novas perspectivas de cuidados ao ser humanos e suas qualidade de viver (Petersen, 2012; Silva \& Sales, 2013; Nogueira, et al., 2018).

A música é como uma linguagem universal que possibilita a relação subjetiva com o ser humano, gerando sentidos, ultrapassando os limites da expressão verbal. Ela se encontra no espaço das emoções, por isso possibilita acesso a conteúdos com os quais a comunicação verbal não se faz suficiente. Nesse viés, percebe-se que as palavras, sentir, música, bom, gente e cantar, refletem a música como forma terapêutica e possibilita estímulo à memória afetiva, podendo se reverter em uma estratégia para a retomada de sentimentos e de lembranças do passado, de sensações prazerosas. Nesse aspecto, estudo mostra que unidades obstétricas, cirúrgicas e psiquiátricas são os locais onde a música atua como terapia que almeja acolher o paciente de uma forma humanizada e permite qualidade de vida dentro das possibilidades (Santee, 2019).

Ainda, Santee (2019) aponta que a música é considerada uma Prática Integrativa e Complementar em saúde, reconhecida como instrumento que promove a humanização, sendo uma tecnologia leve e aplicável em várias unidades de internação. A execução dessa prática também proporciona uma articulação não verbal do paciente e, assim, consequentemente facilita a expressão deste em situações diversas.

Quanto ao acolhimento que foi outra categoria, foi possível notar a música como instrumento capaz de produzir um ambiente que remete ao aconchego e ao conforto. De acordo com Brito (2010), a música é importante no viver e constitui uma das formas de relações que se estabelece consigo mesmo, com o outro, com o ambiente. Dessa maneira, a música destaca-se como recurso de humanização no ambiente hospitalar, sendo este um lugar de desafios e de apreensões. Contudo, a música se apresenta como elemento modificador do ambiente, ao atuar no acolhimento dos pacientes (Nogueira, et al., 2018).

Assim, adentrar-se em aspectos íntimos do ser, trazendo o calor humano, o sentimento de acolhimento e a proximidade das relações humanas, amenizando as angústias, possibilita aflorar sentimentos e emoções que permitem enxergar o hospital como um ambiente humano, caloroso e acolhedor (Mirza, 2016; Nogueira, et al., 2018).

Percebe-se que a música apresenta um importante papel por melhorar a qualidade de vida dos pacientes e também suas relações interpessoais. Por outro lado, traz benefícios para a comunidade hospitalar por transformar o ambiente normalmente informal em um espaço agradável e humanizado (Nascimento \& Crepalde, 2015).

De uma forma dinâmica, o pensamento musical é elaborado, sendo que o verdadeiro sentido se estabelece a partir do momento em que a música se torna parte fundamental do jogo do viver, da vida em si mesma. O dia a dia do viver atualiza o fazer musical que, por outro lado, realimenta e provoca transformações no cotidiano (Brito, 2010). A música cumpre um papel fundamental na transformação do ambiente, por contribuir no alívio da tensão, proporcionando uma sensação de paz, de conforto, de alegria, de tranquilidade, de descontração e de bem-estar (Araújo, 2018). 
Com referência à categoria influência no estado emocional e recordações, percebe-se que a música evoca emoções e desperta sentimentos. Ao comparar esse achado com outros estudos, nota-se que, após a escuta musical, há um aumento do estado de ânimo, de sensação de calma e de alegria. Nota-se a diminuição significativa das sensações de tristeza, de chateação, de preocupação, o que enfatiza a importância dessa intervenção nos cuidados de enfermagem com os pacientes (Bergold \& Alvim, 2011; Campos \& Nakasu, 2016; Rohr \& Alvim, 2016; Araújo, 2018).

Além disso, a música tem característica evocativa, capaz de despertar as recordações e ainda de levar os pacientes a reviverem momentos inesquecíveis, cujos traços da temporalidade subjetiva dos sujeitos evoca lembranças interligadas à história da vida pessoal e familiar. Presencia-se nos depoimentos o resgate das memórias remotas e atuais adquiridas dos vínculos familiares, sociais e dos relacionamentos amorosos construídos ao longo da vida (Albuquerque, et al., 2012; Petersen, 2012; Araújo, et al., 2018).

A música possui o potencial de tocar as pessoas de um modo particular e profundo, o que conduz a reflexões, produzindo mudanças nos relacionamentos interpessoais e nos sentimentos, sendo que a tristeza, proveniente do afastamento de casa, é por vezes minimizada pela música, o que leva à alegria (Silva, et al., 2019).

\section{Conclusão}

Atualmente, a música é um recurso inovador no ambiente hospitalar que contribui na humanização da assistência de enfermagem, ao possibilitar a transmissão do calor humano, do acolhimento e da proximidade das relações humanas. O presente estudo permitiu entender o significado da música para os pacientes hospitalizados no período pós-operatório por meio das categorias abordadas: música e espiritualidade, acolhimento, influência no estado emocional e recordações, sendo a música um instrumento capaz de evocar emoções e despertar sentimentos, favorecendo ao bem-estar e a alegria e produzindo um ambiente que remete ao aconchego e ao conforto.

O tamanho da amostra é uma das limitações do presente estudo, em razão das perdas inevitáveis em decorrência da alta hospitalar que ocorre logo após o procedimento cirúrgico. Além disso, a comparação do estudo com desenho e amostra semelhantes não foi possível, sendo essencial o desenvolvimento de novos estudos sobre a temática abordada. Por outro lado, mesmo com as limitações, este estudo contribui para alcançar evidências científicas que possam mostrar a relevância da música no contexto hospitalar, especialmente no período pós-operatório.

\section{Referências}

Albuquerque, M. C. D. S., Nascimento, L. O. D., Lyra, S. T., Trezza, M. C. S. F. \& Brêda, M. Z. (2012). Os efeitos da música em idosos com doença de Alzheimer de uma instituição de longa permanência. Revista Eletrônica de enfermagem, 14(2), 404-413. doi:http://dx.doi.org/10.5216/ree.v14i2.12532.

Araújo, A. D. S. C., de Medeiros Correia, A., Rodrigues, D.P., Lima, L.M., de Santana Gonçalves, S. \& da Silva Viana, A.P. (2018). Métodos não farmacológicos no parto domiciliar. Revista de Enfermagem UFPE on line, 12 (4), 1091-1096. doi:https://doi.org/10.5205/1981-8963-v12i4a230120p10911096-201.

Bardin, L. (2011). Análise de conteúdo. São Paulo: Edições, 70, 229 p.

Bergold, L. B. \& Alvim, N. A. T. (2011). Influência dos encontros musicais no processo terapêutico de sistemas familiares na quimioterapia. Texto \& Contexto-Enfermagem, 20(SPE), 108-116. doi: http://dx.doi.org/10.1590/S0104-07072011000500014.

Brito, T.A. (2010). Ferramentas com brinquedos: a caixa da música. Revista da ABEM, 24, 89-93.

Campos, L.F. \& Nakasu, M.V. (2016). Efeitos da Utilização da Música no Ambiente Hospitalar: revisão sistemática, Revista Sonora, 6(11),9-19.

Costa, M.C.S. Rossi, L.A. Lopes, L.M. \& Cioffi C.L. (2008). Significados de qualidade de vida: análise interpretativa baseada na experiência de pessoas em reabilitação de queimaduras. Revista Latino-Americana de Enfermagem, 16(2):252-9. doi: https://doi.org/10.1590/S0104-11692008000200013

Folstein, M. F. Folstein, S. E. \& McHugh, P.R. (1975). "Mini-mental state". A practical method for grading the cognitive state of patients for the clinician. J Psychiatr Res, 12(3), 189-198. doi: 10.1016/0022-3956(75)90026-6.

Minayo, M.C.S. (2010). O desafio do conhecimento: pesquisa qualitativa em saúde. São Paulo: Hucitec, 406p. 
Research, Society and Development, v. 10, n. 7, e27710716359, 2021

(CC BY 4.0) | ISSN 2525-3409 | DOI: http://dx.doi.org/10.33448/rsd-v10i7.16359

Mirza, N.M. (2016). Emotions, Development and Materiality at School: a Cultural-Historical Approach. Integrative Psychological and Behavioral Science, 50, 634-654. doi: 10.1007/s12124-016-9348-4

Nascimento, C. A. A. \& Crepalde, N. J. (2015). A música como recurso nos processos de humanização hospitalar. Formação Docente, 7(1), 24-35. doi: https://doi.org/10.15601/756.

Nogueira, C. M., Oliveira, L. F., Gimenes, F. R. E., Fava, S. M. C. L. \& Anjos, A. C. Y. D. (2018). The meaning of music in the vision of the hospitalized person. International Journal of development research, 8(10), 23335-23339.

Petersen, E. (2012). Buscando novos sentidos à vida: musicoterapia em cuidados paliativos. Revista Hospital Universitário Pedro Ernesto, 11(2),63-69.

Rohr, R. V. \& Alvim, N. A. T. (2016). Intervenções de enfermagem com música: revisão integrativa da literatura. Revista de Pesquisa, Cuidado é Fundamental Online, 8(1), 3832-3844.

Santee, K. M., Oliveira, T. S., Santos, T. R., Lima, M. R. G., da Silva Fernandes, C. N. \& Pilger, C. (2019). O uso da música nos serviços de saúde: uma revisão integrativa. Journal of Nursing and Health, 9(2), e199201. doi: https://doi.org/10.15210/jonah.v9i2.14432

Seki, N. H. \& Galheigo, S. M. (2010). O uso da música nos cuidados paliativos: humanizando o cuidado e facilitando o adeus. Interface-Comunicação, Saúde, Educação, 14(33), 273-284. doi: https://doi.org/10.1590/S1414-32832010000200004

Silva, P.C. S., Nogueira, C. M., Oliveira, L. F., Santos, J., Severino, A., Duarte, B. \& Giuliani, C. D. (2019). Music perception of patients in the preoperative period. International Journal of Development Research, 9(11), 31914-31918.

Silva, V. A. D. \& Sales, C. A. (2013). Encontros musicais como recurso em cuidados paliativos oncológicos a usuários de casas de apoio. Revista da Escola de Enfermagem da USP, 47(3), 626-633. doi:https://doi.org/10.1590/S0080-623420130000300015.

Stamenkovic, D.M., Rancic, N.K., Latas, M.B., Neskovic, V., Rondovic, G.M., Wu, J.D. \& Cattano, D. (2018). Ansiedade pré-operatória e implicações na recuperação pós-operatória: o que podemos fazer para mudar nossa história. Minerva anestesiologica,84 (11), 1307-1317. doi: 10.23736/S03759393.18.12520-X

Trindade, A. P. N. T. D., Barboza, M. A., Oliveira, F. B. D. \& Borges, A. P. O. (2013). Repercussão do declínio cognitivo na capacidade funcional em idosos institucionalizados e não institucionalizados. Fisioterapia em Movimento, 26(2), 281-289. doi: https://doi.org/10.1590/S0103-51502013000200005

Teixeira, M. M. R., Paula, J. M. D., Vidal, L. M., Porto, J. A. S., Júnior, B. \& Vidal, C. E. L. (2018). Efeitos Da Música No Pós-Operatório De Pacientes Hospitalizados. Rev Med Minas Gerais, 28(8), e-1929. doi:http://dx.doi.org/10.5935/2238-3182.20180071.

Wazlawic, P. (2006). Quando a música entra em ressonância com as emoções: significados e sentidos na narrativa de jovens estudantes de musicoterapia. Revista Científica/FAP,1,13. 